\title{
Challenges for MANAging COMPleX Application PORTFOlios: a CASE STUdy OF South Australian Public Sector Agency
}

\author{
Yaser Mirza \\ Department of Information Technology \& Mathematical Sciences, \\ University of South Australia, Adelaide, Australia
}

\begin{abstract}
This research explores the challenges in management and the root cause for complex application portfolios in the public sector. It takes Australian public sector organisations with the case of South Australia Police (SAPOL) for evaluation it being one of the significant and mission critical state government agencies. The exploratory research surfaces some of the key challenges using interview as primary data collection source, along with archive records, documentation, and direct observation as secondary sources. This paper reports on the information analysed surfacing eight key issues. It highlights that the organic growth of the technology portfolios, with mission criticality has resulted in many quick fixes which are not aligned with long term enterprise architectural stability. Integration of different mismatched technologies, along with the pressure from the business to always keep the lights on, does not provide the opportunity for the portfolios to be rationalised in an ongoing way. Other issues and the areas for further study are explored at the end.
\end{abstract}

\section{KEYWORDS}

Public Sector IT, Application Portfolio Management, South Australia Police, SAPOL, Government Application Portfolio Challenges, Technology in Policing

\section{INTRODUCTION}

This research is examines some of the critical challenges and the factors behind the creation of complexities in the application portfolios in public sector agencies in South Australia. At the time of an empirical research conducted by the researcher on better technology management in South Australia Police department (SAPOL), the thing that needed consideration was understanding that how can SAPOL's application portfolio that is being pushed on to the cloud environment, rationalised to reduce cost and increase operational efficiency. As the cost of the cloud services is directly proportional to the scale and extent of use via different services and applications used by the organisation [14], the more candidate applications that were transitioned to the cloud meant that the organisation would bare more cost for hosting this huge number of application. Thus, in a drive to reduce this ongoing cost of hosting on the cloud, the organisation strived to rationalise the portfolio to limit any cost overheads for technology's budget. This is nothing new as Public sector is continuously looking for mechanisms to reduce operating costs while maintaining high service quality for the consumers [14]. As a first step to rationalise the complexities of the portfolio, it needs to be understood the root causes for these complex portfolios. This research which is a part of a bigger empirical research studies the some of the challenges and the root cause for the un-rationalised portfolios in public sector organisations in Australian public sector, taking South Australia Police department (SAPOL) as the unit of analysis. 
International Journal of Managing Information Technology (IJMIT) Vol.13, No.3, August 2021

According to [1] government agencies must manage large and complex application portfolios which is not very different to private organisations. Many of these implementations represent very high investment and ongoing use of resources [2]. In initial assessment it was evident that the way public sector organisations operate is different private sector organisations due to the nature of the machinery of government and the bureaucrats involved in processes. A lot of things that may seem applicable within the private sector organisations can become extremely challenging when the same implementation is evaluated for public sector organisations. SAPOL has a staff strength of 6000 [13] and the SAPOL IT application portfolio came up with over 400 applications serving different functions of the organisation at different times with varying level of utility for the agency. [3] suggest that large enterprises may have hundreds of separate but interrelated applications aiming to improve specific parts of the business. According to [4] portfolio simplification is required for reducing costs, increasing service levels and reducing complexity in organisations. The complexity of technology solutions comes with many challenges and requires a portfolio-based approach to meet some of them [2]. According to [5], in the recent years, organisations have faced challenges in managing growing complex application landscapes. [3] emphasise that research in managing application portfolios will result in valuable findings. [2] organisations have accumulated a large collection of Information Technology solutions to achieve efficiency.

\section{Data Collection ApProach}

The specifics for large, complex, and organic portfolios in the public sector, were evaluated with the help of the literature review, interviews, and direct observation at SAPOL. Some of the challenges and their background in the organisation related to managing complex application portfolio in SAPOL were established. To evaluate this, semi structured open ended, explorative expert interviews were conducted with the SAPOL CIO on 6th October 2016 and Manager Architecture Business consulting and Software Operations on 14th October 2016. The data collection including interviews was conducted over a period of six months from July 2016 to January 2017. The interviewees were selected based on their relevance to the topic and their role in the organisation under study.

Table 1. Interviews for Data Collection.

\begin{tabular}{|l|l|l|l|l|l|}
\hline $\begin{array}{l}\text { Interview } \\
\text { Subject }\end{array}$ & Interview Type & Interviewee & $\begin{array}{l}\text { Recording } \\
\text { mechanism }\end{array}$ & Date & $\begin{array}{l}\text { Dura } \\
\text { tion }\end{array}$ \\
\hline $\begin{array}{l}\text { Application } \\
\text { Portfolio } \\
\text { Rationalisatio } \\
\mathrm{n}\end{array}$ & $\begin{array}{l}\text { Standardised open-ended } \\
\text { interview - Semi-structured } \\
\text { explorative expert interview } \\
\text { Appendix 10 }\end{array}$ & $\begin{array}{l}\text { CIO / Director } \\
\text { IS\&T }\end{array}$ & $\begin{array}{l}\text { Meeting } \\
\text { email, Minutes } \\
\text { of meeting, }\end{array}$ & $06 / 10 / 2016$ & $\begin{array}{l}1 \\
\text { hour }\end{array}$ \\
\hline APM & $\begin{array}{l}\text { Standardised open-ended } \\
\text { interview - Semi-structured } \\
\text { explorative expert interview } \\
\text { Appendix 10 }\end{array}$ & $\begin{array}{l}\text { Manager ABC } \\
\text { and Manager } \\
\text { Software } \\
\text { Operations. }\end{array}$ & $\begin{array}{l}\text { Meeting } \\
\text { email, Minutes } \\
\text { of meeting, }\end{array}$ & $14 / 10 / 2016$ & $\begin{array}{l}40 \\
\text { mins }\end{array}$ \\
\hline
\end{tabular}

The questionnaire for this interview is listed in table 2 below.

Table 2. Interview Questionnaire.

\begin{tabular}{|l|l|l|}
\hline$\#$ & Question Description & Time Allocated \\
\hline 1 & $\begin{array}{l}\text { How did the information technology application portfolios become so } \\
\text { complex? Can you please share your understanding? }\end{array}$ & $10 \mathrm{~min}$ \\
\hline 2 & $\begin{array}{l}\text { What are some of the biggest challenge in managing the application } \\
\text { portfolios? }\end{array}$ & $10 \mathrm{~min}$ \\
\hline
\end{tabular}


International Journal of Managing Information Technology (IJMIT) Vol.13, No.3, August 2021

\begin{tabular}{|l|l|l|}
\hline 3 & $\begin{array}{l}\text { What actions are required to improve the application portfolios } \\
\text { complexities? }\end{array}$ & $10 \mathrm{~min}$ \\
\hline 4 & $\begin{array}{l}\text { Would you like to provide any other advice in regard to application portfolio } \\
\text { rationalization at SAPOL? }\end{array}$ & $5 \mathrm{~min}$ \\
\hline
\end{tabular}

\section{FINDINGS}

An interpretation of the interviews is given below.

\subsection{Organic Growth \& Quick Wins}

Information technology does not just only provide a supporting function to the business but also enables the core business functions. Due to this great need for Information Technology as an arm for the business organisations have expanded their information technology portfolios massively. Over the period Information Technology portfolios has brought many advantages to the business yet at the same time it has brought its own challenges. The rapidly changing technology, increasing cost of technology implementations and the time required for these implementations are becoming a challenge for technology stake holders [6].

Before we can access the details of the challenges, we must understand how we have eventually come to this point in terms of our portfolio growth. In the technology journey for many organisations till this point of time, many of the organisations have followed and organic growth process within Information Technology. According to SAPOL CIO, technologies have established very fast pace in order to respond to the business requirements and to solve business problems. In this whole process what has happened is that quick fixes and solutions have been adapted to fix the current problems faced by the business at that point of time. In such situations due to the urgent nature of business needs, the whole architectural point of view and strategic direction may not have been considered in those technology implementations. Because of this evolving nature of technologies and this fast pace of technology implementations we have ended up with organisations which have got a massive amalgam of Technologies which is very widely spread over various platforms tools and solutions.

\subsection{Sustaining Integrations of Non-Standard Portfolio}

The sustainability of such massively integrated solutions has always become a point of question. With the expanding integrations of various flavours of technologies there comes a problem of sustainability and the quality of the integrated systems. The Manager Software Operations highlights that these being production and business critical systems, a massive correction or introduction of standards into the ecosystem post implementation is not feasible. Thus, mostly the most appropriate tactical decision at the time is the one that enables the patchy integration irrespective of the architectural alignment and technology strategy. Over the period of time, the organisation has gone through numerous such integrations which were not completely compatible and sustainable in the long run, but to cater for the current business need at the time, decision in the favour of such implementations took place repeatedly.

\subsection{Increasing Operational Costs of IT Portfolio}

So, on the surface, having this technology portfolio with a lot of things of different flavours of tools, platforms and solutions with massive integrations does not appear as a show stopper. This is due to the perception that everything is under control and is working fine. The Manager Software Operations explains that under the surface, just keeping the lights on and making everything stay operational is much cost and resource extensive. It takes a lot of effort from the 
International Journal of Managing Information Technology (IJMIT) Vol.13, No.3, August 2021

information technology stakeholders just to manage the complexity of the portfolio and keeping it up and running. Application portfolio rationalisation can reduce the cost of IT operations and the time and cost saved in the process can be utilized in the areas that need more immediate attention [15]. The cost that is saved in this process is hard to predict as a general rule and depends deeply upon the current state or the unrationalised organisational technology portfolio, the strategy and tools applied for rationalisation and implementation approach in line with the technology road map[16]. SAPOL CIO also believes that the effort on information technology operations and maintenance becomes massive and does not leave a lot of capacity for new initiatives and technology-driven desired transformations for the business. Thus, technology cannot take a leading role in business outcomes or benefit the business to the best of its potential.

\subsection{Business Expectations}

In an ideal situation, maximum revenue, investments and efforts are bent on the new initiatives and getting the competitive advantage rather than just keeping the wheel moving. According to the Manager Architecture,

"Innovative solutions require time, resources and funding, but if most of it is spent on managing the operational applications, we cannot be ahead of the game".

This is where information technology management comes under a lot of pressure because just running information technology operations is not something that should consume most of the Information Technology spending. The problem is that the value that is being brought by Information Technology stays the same as last year but the effort that goes on in getting a just exponentially grows with everyday increase in complexity mesh of Solutions. This inevitably brings technology stakeholders to the position where they are looked at by the business as not doing enough not being able to give the desired results in gaining competitive advantage where there's not a lot of capacity to do so because most of the capacity is utilised by keeping the operations and lights on.

\subsection{Irrationalised Portfolios}

According to Manager Software Operations [7], for large enterprises the typical application portfolios have grown over the decades and the number of applications can be as high as 500 . The Manager Software Operation explains that these 500 applications may have been made by different vendors and they were not meant to work in integration with each other [7]. This information is encapsulated from the business and the business requires these services being delivered by Information Technology irrespective of the underlying complexities. This results in massive functional overlaps and irrationalised portfolio. As most of the applications are being used by different business functions in partial ways, some of their components if utilised centrally can be useful for some other business functions. But due to the lack of visibility of this massive forest of functionality, a lot or repetition and waste is introduced in the system.

According to [8] many government agencies have redundant functionalities in their complex application portfolios. According to [9] many of the government organisation's application portfolio also includes redundant functionalities which can be eliminated to improve efficiency, performance and reduce cost. According to [9] in government agencies, the adjoining complexities need to be identified to effectively ascertain redundant functionalities. Due to the changing business requirements, organisations eventually end up gathering a multi-vendor multiplatform collection of Information Technology applications and solutions without a formal roadmap for the future and integrations [2]. It is not uncommon to have multi sourced solutions not relying upon the common architecture, which are put in place for short term reliefs but in the 
International Journal of Managing Information Technology (IJMIT) Vol.13, No.3, August 2021

long run, the price of these quick wins has to be paid while managing these huge portfolios of Information Technology applications [2].

\subsection{Limited Enterprise Architectural Focus}

Manager Enterprise Architecture stated on the interview on 14 October 2016 that,

"Enterprise Architecture focus has to be the key to managing and rationalizing the application portfolios. Any rationalisation practice in the absence of this would inevitably result in a similar situation over the period of time. We have all seen this happen"

These solutions may be technically the right fit for the business at that point of time, but they can clearly lack maturity with respect to the overall technology architecture and strategy. As the various business functions and intertwined and related, thus the level of integration required by technology needs to correspond to that need. Technology stake holders need to understand the business and their interrelated dependencies between different business functions [6].

In the discussion with the Manager Enterprise Architecture at SAPOL, some of the other related problems that can be managed with enterprise architecture focus for the application portfolios include:

- Fast Growth and increasing complexity of application portfolios

- Decentralised control of the organisation's application portfolio

- Visibility of complete portfolio including business and technical ownership

- Unclear Roadmap for technology portfolio

- Inaccurate information and missing information

- Management of application portfolio with tools, processes, and resources

\subsection{High Availability Business Requirements}

One reason for this requirement is that the businesses cannot afford significant downtimes in order to bring these pieces of technology in synchronisation and adhere to standards. On the other hand, the big bang approach to replace everything with something that works much better in a standard uniform way comes with huge risks of its own of significant service interruptions. Depending upon the criticality of business for different public service agencies, this may not be very palatable for many agencies. The Manager Software Operations in his interview on 14th October 2016 told the researcher that,

"SAPOL is a mission critical organisation where our applications support our frontline coppers, and downtime on the applications can compromise the safety of the community and our members of the police. We cannot afford slippages and failures in our technology stack".

There is constant pressure for organisations to better plan and implement their technology portfolios due to the importance to the business outcomes [6].Due to this massive challenge technology leaders within the organisations have always been under the pressure of providing ongoing service and keeping the lights on becomes the top priority for many technology leaders. So, with every passing year come into existence new technology solutions which may be the quickest and the best fit at that point of time, but they keep on adding to the existing diversity of the technology portfolio. 
International Journal of Managing Information Technology (IJMIT) Vol.13, No.3, August 2021

\subsection{Application Portfolio Rationalisation Practices}

One thing that SAPOL and other organisations that are going through a similar situation need to focus on is establishment of application portfolio management and rationalisation practices. Although the planning of the information systems can considerably assist in a more refined schema for managing the technology portfolios, yet different organisations have made attempts to launch planning activities for information systems and ended up without substantial results [6]. Manager Software Operations at SAPOL said in his explorative expert interview on 14th October 2016 that,

"Although portfolio rationalisation is a resource intensive task that can only take place in its own time, it is still worth it for the savings it offers in return. This is not a quick fix, but an ongoing work required to ensure that the existing problems can be clearly identified."

According to [10] and [1] rationalisation of the application landscape can result in saving money. According to [1] as the size and complexity of the application portfolio is reduced with the help of application portfolio rationalisation process, the costs of managing the portfolio correspondingly comes down. The planning of the systems requires constant revisions as different outcomes appear at different times to realign the rationalisation activities with the strategic goals. This can be a time consuming and resource intensive task as it is not a one-time task [6].

Once these problems are appreciated, according the Manager Architecture and Business Consulting at SAPOL, a logical implementation approach can be taken from enterprise architectural perspective to fix these problems one by one. At the end of the day, this effort into fixing the portfolio will deliver us more capacity to focus on fresh initiatives and become business enablers.

According to [9] up to 80 percent of Information Technology budget is spent on maintaining existing complex application portfolio. This further highlights the importance of technology portfolio planning in larger organisations [6]. According to [9] APM can be used to simplify the application portfolio.

\section{CONClusion \& FURTHER WORK}

This research evaluates the some of the challenges and the root cause for the complexity of IT portfolios at Australian public sector agencies taking SAPOL as the unit of analysis. Using interviews as primary source of data collection some key reasons behind the current state of the 400+ application portfolio, were established to be as: organic growth over the period of time; due to high business availability requirements quick wins resulting in patchy work; sustaining integrations of nonstandard portfolios which added more to the problems increasing operational cost; and last but not least, a limited focus on the enterprise architecture which overall resulted in an irrationalised application portfolio.

This research can assist technology managers and key stakeholders to have a retrospective view in the organic application growth process and gain a valuable lesson to ensure these complexities in the application portfolios can be avoided in their respective portfolios. Technology Managers and CIOs can make better informed decisions by learning from the findings of this research and ensure a better long term strategic technology road map. Such gains can assist organisational technology functions to focus their budget and energies more on innovation, problem solving and serving the business rather than constantly battling against the complexity challenges. Especially 
International Journal of Managing Information Technology (IJMIT) Vol.13, No.3, August 2021

in the public sector, agencies can learn from this specific case study of South Australia police and apply the lessons learned to their organisations due to the similarity of the government processes and technology portfolio expectations to deliver high level of uninterrupted services with the growing budget constraints every year.

- For future research, this logically brought me to the next step of understanding that how can these problems in public sector application portfolios be fixed.

- Better application portfolio management will provide clear visibility into our assets and cost centres. SAPOL can know exactly, their capabilities in the existing portfolio as well as its alignment and coverage with the business.

- Further research within public sector in Australia yet beyond the organisation is encouraged.

- Quantitative analysis of the data in the subsequent studies can reinforce the study outcomes.

\section{ACKNOWLEDGEMENTS}

The authors would like to thank South Australian Government and SAPOL for allowing this empirical research in the organisation and University of South Australia for supporting this research. The author would also like to thank the interview participants at SAPOL for giving their valuable inputs to this research.

\section{REFERENCES}

[1] Gietema, S., Bos, R. \& Brinkkemper, S. 2012, "Reducing IT Related Costs Using Application Portfolio Rationalization: A Study Focusing on Reducing Application Portfolio Size And Complexity in Small Municipalities", Academic Conferences International Limited, Kidmore End, vol.6, pp. 268.

[2] Cosman, E.C. 2015, "A portfolio approach to operations IT solutions management", Hydrocarbon Processing, viewed $\quad$ on 09 Aug 2021, <https://www.hydrocarbonprocessing.com/magazine/2015/december-2015/columns/hp-automationstrategies-a-portfolio-approach-to-operations-it-solutions-management> .

[3] Riempp, G. \& Gieffers-Ankel, S. 2007, "Application portfolio management: a decision-oriented view of enterprise architecture", Information Systems and eBusiness Management, vol. 5, no. 4, pp. 359.

[4] Zygband, P., Tummalapalli, V., \& Stenger, J. 2009, "Optimizing the Software Portfolio", Supply Chain Management Review, vol. 13, no. 8, pp. 49.

[5] Simon, D., Fischbach, K., \& Schoder, D. (2010). Application Portfolio Management -An Integrated Framework and a Software Tool Evaluation Approach. Communications of the Association for Information Systems, 26, pp-pp.

[6] McFarlan, F.W., McKenney, J.L. \& Pyburn, P. 1983, The Information Archipelago - Plotting a Course, Harvard Business Review, Boston.

[7] SAPOL 2017, Minutes of Meeting APM. Internal SAPOL Document. Unpublished

[8] Fabriek, M., Brinkkemper, S., and van Dullemen, J. 2007, "A Method for Application Portfolio Rationalization," Proceedings of the 2nd International Conference on Digital Information Management, pp. 466-472.

[9] Kara, V. and Paidi, V.P. 2011, "Reducing redundant functionalities of an application portfolio - Case Study Swedish Municipality", Master Thesis, öRebro University, Swedish Business School.

[10] Gittlen, S. 2016 "Trim your application portfolio for savings", Computerworld, 2 May, viewed November 2017, <https://www.computerworld.com/article/3060854/enterprise-applications/trimyour-application-portfolio-for-savings.html >

[11] Landmesser, J.A. 2014, Improving it portfolio management decision confidence using multi-criteria decision making and hypervariate display techniques, Nova Southeastern University.

[12] van Angeren, J., Blijleven, V. \& Batenburg, R. 2014, "Application Portfolio Management in Hospitals: Empirical Insights", International Journal of Healthcare Information Systems and Informatics, vol. 9, no. 1, pp. 61-74. 
International Journal of Managing Information Technology (IJMIT) Vol.13, No.3, August 2021

[13] SAPOL 2018, SAPOL Public Website, viewed on 09 Aug 2021, 〈https://www.police.sa.gov.au〉.

[14] Cho, S, Hwang, S, Shin, W, Kim, N \& In, HP 2021, 'Design of Military Service Framework for Enabling Migration to Military SaaS Cloud Environment', Electronics, vol. 10, no. 5, p. 572, accessed from <http://dx.doi.org/10.3390/electronics10050572>.

[15] Kovácsné Mozsár, A.L. and Michelberger, P., 2018. IT risk management and application portfolio management. Polish Journal of Management Studies, 17.

[16] Kovacsne, L. A. M. (2017). Reducing IT costs and ensuring safe operation with application of the portfolio management. Serbian Journal of Management, 12(1), 143-155.

\section{AUTHOR}

Dr. Yaser Mirza is an academic, researcher, technology professional and an entrepreneur with over seventeen years of experience working in public and private sector across different agencies in Asia, Middle East, and Australia. He is recent experience has been with Government of Australia in various technology management roles, along with parallel academic affiliation with University of South Australia and Federation University Australia.

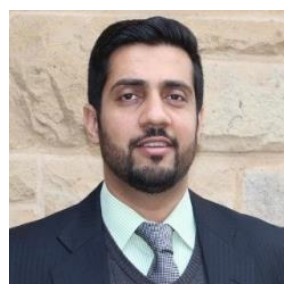

